\title{
Demand Analysis of Non-Alcoholic Beverages in Japan
}

\author{
Michael Fesseha Yohannes ${ }^{1} \&$ Toshinobu Matsuda ${ }^{2}$ \\ ${ }^{1}$ United Graduate School of Agricultural Sciences, Tottori University, Japan \\ ${ }^{2}$ Faculty of Agriculture, Tottori University, Japan \\ Correspondence: Toshinobu Matsuda, Faculty of Agriculture, Tottori University, Japan. E-mail: \\ matsudat@muses.tottori-u.ac.jp
}

Received: February 12, 2015 Accepted: March 15, 2015 Online Published: April 15, 2015

doi:10.5539/jas.v7n5p143 URL: http://dx.doi.org/10.5539/jas.v7n5p143

\begin{abstract}
This paper estimates the demand of non-alcoholic beverages in Japanese household using the linear approximation quadratic almost ideal demand system model (LA/QUAIDS). Eight expenditure shares and prices demand equations for non-alcoholic beverage group: green tea, black tea, tea beverage, coffee, coffee beverage, fruit and vegetable juice, carbonated beverage and milk are estimated for two or more households in forty-nine cities for the period January 2000 through March 2013. The expenditure elasticity results indicate that green tea (2.320), black tea (1.357), coffee (1.090) and fruit and vegetable juice (1.019) are luxury goods while tea beverage (0.836), coffee beverage (0.896), carbonated beverage $(0.844)$ and milk $(0.677)$ are necessities in the Japanese household. The demographic effects reveal that people under the age of 18 prefer milk (5.928) than any other beverages whereas elderly people tend to drink more green tea (24.427). Moreover, temperature effects shows it has mostly positive effect on demand for tea beverage, coffee beverage, fruit and vegetable juice, and carbonated beverage and negative effect on green tea, black tea, and coffee in most of the months.
\end{abstract}

Keywords: elasticity, Japanese household, LA/QUAIDS, non-alcoholic beverage, temperature effects

\section{Introduction}

The global non-alcoholic beverage industry is one of the biggest in the world with market size of 531.3 billion dollars in 2013 (Euromonitor, 2014). Japan is among the main market in the non-alcoholic beverage market with sales revenue of 31.3 billion dollars in 2013 (Japan Soft Drink Association, 2014). In the Japanese non-alcoholic beverage industry, tea beverage holds the largest market segment (with 5.4 billion liters produced in 2013) and is followed by carbonated beverage (3.6 billion liters in 2013), fluid milk (3.0 billion liters in 2013), coffee beverage (2.9 billion liters in 2013), mineral water (2.8 billion liters in 2013), fruit and vegetable juice (1.7 billion liters in 2013), and sports beverage (1.6 billion liters in 2013). Other smaller categories beverages such as lactic beverage (496.0 million liters in 2013) and soy milk (164.9 million liters in 2013) comprise the remaining share of the beverage group (Japan Soft Drink Association, 2014). In terms of largest market sales globally, Japan has the third largest demand for fruit and vegetable juice after the United States and China with net sales of 10.4 billion dollars in 2012. However, its per capita consumption is lower than many nations at 18 liters (Euromonitor, 2012). Similarly, Japan's consumption per capita for carbonated beverage is also relatively smaller at 28.6 liters in 2013 (Japan Soft Drink Association, 2014). During the same year, the United States' per capita is five times more than Japan's at 165.8 liters (Statista, 2014). Even though, demand for both tea and coffee is significant in the Japanese non-alcoholic beverage industry, its per capita consumption has remained relatively the same since the year 2000 at 1.0 liter and 3.4 liters per person respectively (Helgi Library, 2011, ICO). As for the demand of fluid milk, its per capita consumption shows it has been on a decline for the past decade from 39.0 liters in 2000 to 31.8 liters by 2010 (Ministry of Agriculture, Forestry and Fisheries of Japan). Watanabe and Suzuki (2006) confirmed this validity in their analysis of perceptions and attitudes concerning milk consumption stressing little can be done to increase the demand of milk. Moreover, Schluep Campo and Beghin (2005) pointed out that milk consumption is regular in 80 percent of Japanese household and by 90 percent of the total population, as 4 out 5 Japanese are aware of its high nutritional quality.

There haves been quite few studies that analyzes the demand for non-alcoholic beverages in different countries over the years: Kinnucan, Miao, Xiao, and Kaiser (2001), Yen, Lin, Smallwood, and Andrews (2004), Pofahl, Capps Jr, and Clauson (2005), Zheng and Kaiser (2008), and Dharmasena, Capps Jr, and Clauson (2009) to name 
a few have all analyzed the demand pattern of non-alcoholic beverages in the United States using annual time series data. The numbers of previous studies on demand of non-alcoholic beverages in Japan however are very few. Nonetheless, there are a number of studies that focuses mainly on milk demand. Some of the relevant studies: Watanabe, Suzuki, and Kaiser (1997) examined consumer's preferences of milk and other beverages using Japanese consumer data and Quantification theory type III. Their results indicate that middle-aged people prefer soda and alcoholic beverages to milk beverages while younger people prefer milk. Watanabe, Suzuki, and Kaiser (1998) using a logit model analyzed the consumption of milk for nine beverages in Japan. Their results concluded that many of the consumers attribute had a major relation with the consumption of other beverages. Stroppiana, Riethmuller, and Kobayashi (1998) analyzed the consumption of milk in nine Japanese regions. Their finding indicates that structural factors such as consumer age and size of the household have an effect on the consumption of milk at regional and national level in Japan. Watanabe et al. (2006) estimated demand for milk and other dietary products using Heckman's two-step estimators of the type II Tobit model. Their result shows that higher estimation on milk utility and higher health concerns are significant determinant for milk consumption.

Most of the studies mentioned are related mainly on milk and do not concentrate on other beverages in the Japanese household. Moreover, they do not incorporate a complete demand model in addition to examining a wide range of factors and beverage varieties.

Our study applies a comprehensive demand model for eight expenditure shares and prices in the Japanese non-alcoholic beverages household. Since Japan is one of the biggest producing and consuming nation of non-alcoholic beverages, this study could be a useful tool for beverage manufacturers as well as for policy makers.

Regarding consumption of non-alcoholic beverages, there are several factors that could influence its demand pattern. Some of these factors include expenditure, price, socio-demographic variables, and temperature. Temperature is an important feature of consumer behavior. There have been quite few studies that analyzed temperature effects on consumer demand, to mention some: Harrison (1992), Agnew and Palutikof (1999), Parker and Tavasolli (2000), Roslow, Li, and Nicholls (2000), Murray, Di Muro, Finn, and Popkowski Leszczyc (2010), and Bahng and Kincade (2012). However, these studies do not examine the demand for non-alcoholic beverages with regards to temperature effects. Our study, using the LA/QUAIDS model, attempts to analyze the demand for non-alcoholic beverages in Japanese household. To attain the analysis of this study, we jointly estimate eight demand equations taking into account the effects of demographic and temperature by evaluating the monthly city data for green tea, black tea, tea beverage, coffee, coffee beverage, fruit and vegetable juice, carbonated beverage, and milk. In addition, to a general concern about demand of non-alcoholic beverages in Japanese household, it is a great interest to determine whether the beverages are necessity, luxury, or an inferior good. According to our knowledge, the novelty of the study is it is the first study to analyze temperature effect on non-alcoholic beverages demand in Japanese household.

The rest of the paper is drawn as the following, a discussion of the data set and model, followed by a discussion of the results and lastly the conclusion.

\section{Data and Model}

Monthly aggregate pseudo panel data, which is repeated cross sectional data, is used in this study for two or more person households from January 2000 to March 2013 for 49 cities, attainted from the Family Income and Expenditure Survey (FIES) of Japan, conducted by the Ministry of Internal Affairs. Pseudo panel data, suggested by Deaton (1985), is an alternative econometric method for estimating demand models of individual behavior. One of the advantages of pseudo panel data over panel data is that it allows us to estimate models over a longer period of time. In addition it eliminates individual-level measurement error.

The use of aggregate pseudo panel data enables us to capture the impact of the important demographic and temperature variable affecting non-alcoholic beverages patterns in Japan. Considering the changes in prices, all expenditure data for green tea, black tea, tea beverage, coffee, coffee beverage, fruit and vegetable, carbonated beverage and milk were deflated using the consumer price index. To conduct the estimation process, we used the SHAZAM (version 10.2) econometrics software. A sample size of 7789 is included in this study. The iterative seemingly unrelated regression (ISUR) was used to estimate the linear system of eight equations. To ensure non-singularity of the error covariance matrix, we deleted the 8th equation for milk. We apply two types of dummy variables into the demand system: monthly dummy variables to adjust the monthly variation and city dummy variables to capture the city variation. Several demographic variables from the FIES were incorporated in the study to understand the demand patterns of non-alcoholic beverages in the Japanese households. These 
variables include size (household size), under (number of persons per household under the aged of 18), elders (number of persons per household over the age of 65), age (age of the head), and rent (rate of those paying rent). The study doesn't include variables such as gender and race since those data are not available at the FIES. To assess the temperature effects, monthly data from January 2000 to March 2013 were outsourced from Japan Meteorological Agency.

The quadratic almost ideal demand system (QUAIDS) model, which was developed from utility maximization by Banks, Blundell, and Lewbel (1997), not only holds the desirable properties of Deaton and Muellbauer's (1980) almost ideal demand system (AIDS) model but also is more versatile in modeling consumer expenditure patterns. The QUAIDS model gives rise to quadratic logarithmic Engel curves, that is, allowing such circumstances where incremental in expenditure would change a luxury to a necessity, whereas for the AIDS model, it gives rise to Engel curves that are linear in logarithm of total expenditure. Moreover, for QUAIDS model, the expenditure elasticity depends on the level for expenditure while for the AIDS model the elasticities are not dependent of expenditure level (Banks et al., 1997). The recent applied studies on QUAIDS are presented in Matsuda (2006). For our study purpose, we employ the linear version of QUAIDS (LA/QUAIDS) model by Matsuda (2006). We selected this specific model, LA/QUAIDS, because it features the characteristics of 'Closure Under Unit Scaling' (CUUS) even with demand shifters such as demographic variables and monthly and city dummies (Alston, Chalfant, \& Piggott, 2001). With demand shifters, the original QUAIDS of Banks et al. (1997) does not fulfill CUUS. According to Pollak and Wales (1992), CUUS is a property that ensures that estimated economic effects are constant to the scaling of the data. Moreover, Pollak and Wales (1980) stated that only demand systems consistent with CUUS should be used for empirical demand analysis.

Following Matsuda (2006), the LA/QUAIDS model is derived as:

$$
w_{i}=\alpha_{i}+\sum_{j=1}^{n} \gamma_{i j} \log p_{j}+\beta_{i} \log \frac{y}{P^{C}}+\frac{\lambda_{i}}{P^{Z}}\left(\log \frac{y}{P^{C}}\right)^{2} \quad i=1,2, \ldots, n
$$

where $w_{i}$ is the expenditure share of good $i, y$ is total expenditure within the system, $p_{j}$ is the price of good $j, \alpha_{i}$, $\beta_{i}, \gamma_{i j}$, and $\lambda_{i}$ are parameters to be estimated.

$$
\log P^{C}=\sum_{i} \bar{w}_{i} \log p_{j}
$$

The loglinear analogue of the Laspeyres price index is shown in Equation 2. $P^{C}$ is invariant to changes in units. - stands for the sample mean.

We apply index $P^{Z}$ as proposed by Matsuda (2006) in Equation 3:

$$
\log P^{Z}=\sum_{i=1}^{n}\left(w_{i}-\bar{w}_{i}\right) \log \frac{p_{i}}{\bar{p}_{i}}
$$

where $P^{Z}$ could be seen as a zero degree homogenous analogue of the Törnqvist price index analogue and is likewise invariant to changes units.

We define the estimated LA/QUAIDS model using expenditures shares and prices for the demand of green tea, black tea, tea beverage, coffee, coffee beverage, fruit and vegetable juice, carbonated beverage and milk with regards to demographic, temperature, and other dummy variables as follow:

$$
w_{i}=\alpha_{i 0}+\alpha_{i 1} t+\sum_{k=1}^{6} \alpha_{i, 1+k} Z_{k}+\sum_{m=1}^{11} \alpha_{i, 7+m} D_{m}+\alpha_{i 19} h+\sum_{r=1}^{48} \alpha_{i, 19+r} M_{r}+\sum_{j=1}^{8} \gamma_{i j} \log p_{j}+\beta_{i} \log \frac{y}{P^{C}}+\frac{\lambda_{i}}{P^{Z}}\left(\log \frac{y}{P^{C}}\right)^{2} \quad i=1,2, \ldots, 8
$$

where $t$ indexes the time in months, $Z_{k}$ are demographic variables, $D_{m}$ are monthly dummy variables, $h$ is temperature, $M_{r}$ are city dummy variables. The parameters consequently are expected to meet the following restrictions:

$$
\begin{gathered}
\sum_{i=1}^{8} \alpha_{i 0}=0 \quad \sum_{i=1}^{8} \alpha_{i k}=0 \quad k=1,2, \ldots, 67 \\
\sum_{i=1}^{8} \beta_{i}=0 \\
\sum_{i=1}^{8} \lambda_{i}=0 \\
\sum_{i=1}^{8} n_{i j}=0 \quad j=1,2, \ldots, 8 \\
\sum_{j=1}^{8} \gamma_{i j}=0 \quad i=1,2, \ldots, 8
\end{gathered}
$$

The ensuing demand system jointly ensures that it fulfills adding up and homogeneity. In addition, symmetry is 
guaranteed by the additional restriction:

$$
\gamma_{i j}=\gamma_{j i} \quad i, j=1,2, \ldots, 8
$$

The expenditure, uncompensated, and compensated price elasticities can be calculated as follows:

$$
\begin{gathered}
\varepsilon_{i}=1+\frac{\beta_{i}}{w_{i}}+\frac{2 \lambda_{i}}{w_{i} P^{Z}} \log \frac{y}{P^{C}} \quad i=1,2, \ldots, 8 \\
\varepsilon_{i j}=-\delta_{i j}+\frac{\gamma_{i}}{w_{i}}-\frac{\beta_{i} \bar{w}_{j}}{w_{i}}-\frac{\lambda_{i}}{w_{i} P^{Z}}\left[2 \bar{w}_{j}+\left(w_{j}-\bar{w}_{j}\right) \log \frac{y}{P^{C}}\right] \log \frac{y}{P^{C}} \quad i, j=1,2, \ldots, 8 \\
\varepsilon_{i j}^{c}=\varepsilon_{i j}+\varepsilon_{i w_{j}} \quad \text { (Slutsky equation) } \quad i, j=1,2, \ldots, 8
\end{gathered}
$$

Where $\delta_{i j}$ is the Kronecker delta: $\delta_{i j}=1$ for $i=j ; \delta_{i j}=0$ for $i \neq j$.

\section{Results}

Table 1 reports the descriptive statistics of variables. The expenditure share of milk (0.371), fruit and vegetable juice $(0.184)$ and coffee $(0.107)$ show they have the highest mean expenditure shares whereas black tea $(0.018)$ and carbonated beverage $(0.057)$ have the lowest mean expenditure shares in the household.

Table 1. Descriptive statistics of variables

\begin{tabular}{lllll}
\hline Variables & Mean & Std. deviation & Minimum & Maximum \\
\hline Number of persons per household $\left(z_{1}\right)$ & 3.126 & 0.184 & 2.58 & 4.13 \\
Number of persons per household under the age of $18\left(z_{2}\right)$ & 0.682 & 0.139 & 0.22 & 1.3 \\
Number of persons per household over the age of $65\left(z_{3}\right)$ & 0.611 & 0.126 & 0.21 & 1.38 \\
Age of the head $\left(z_{4}\right)$ & 54.848 & 2.571 & 47.00 & 64.00 \\
Rate of those paying rent $(\%)\left(z_{5}\right)$ & 24.204 & 9.354 & 0.0 & 56.8 \\
Expenditure share of green tean $\left(w_{1}\right)$ & 0.100 & 0.059 & 0.01 & 0.638 \\
Expenditure share of black tea $\left(w_{2}\right)$ & 0.018 & 0.013 & 0 & 0.223 \\
Expenditure share of tea beverage $\left(w_{3}\right)$ & 0.098 & 0.036 & 0 & 0.235 \\
Expenditure share of coffee $\left(w_{4}\right)$ & 0.107 & 0.040 & 0 & 0.358 \\
Expenditure share of coffee beverage $\left(w_{5}\right)$ & 0.065 & 0.026 & 0.01 & 0.195 \\
Expenditure share of fruit \& vegetable juice $\left(w_{6}\right)$ & 0.184 & 0.043 & 0.02 & 0.47 \\
Expenditure share of carbonated beverage $\left(w_{7}\right)$ & 0.057 & 0.025 & 0.01 & 0.18 \\
Expenditure share of milk $\left(w_{8}\right)$ & 0.371 & 0.061 & 0.15 & 0.76 \\
Price of green tea $\left(p_{1}\right)$ & 101.670 & 3.819 & 87.92 & 118.39 \\
Price of blacke tea $\left(p_{2}\right)$ & 106.300 & 6.909 & 86.59 & 132.73 \\
Price of tea beverage $\left(p_{3}\right)$ & 112.890 & 15.28 & 87.62 & 159.87 \\
Price of coffee $\left(p_{4}\right)$ & 103.390 & 9.72 & 81.26 & 145.06 \\
Price of coffee beverage $\left(p_{5}\right)$ & 109.870 & 9.28 & 87.10 & 138.36 \\
Price of fruit \& vegetable juice $\left(p_{6}\right)$ & 105.950 & 7.59 & 88.14 & 135.27 \\
Price of carbonated beverage $\left(p_{7}\right)$ & 114.570 & 14.00 & 84.33 & 149.42 \\
Price of milk $\left(p_{8}\right)$ & 95.693 & 4.77 & 79.73 & 109.34 \\
Temperature $(h)$ & 15.324 & 8.34 & -5.70 & 30.50 \\
\hline
\end{tabular}

Table 2 reports the estimates of expenditure and price coefficients at the mean shares. The price coefficients for green tea (-0.127), tea beverage (-0.103), coffee beverage (-0.019), fruit and vegetable juice $(0.042)$, and carbonated beverage (-0.133) are statically significant at the 1 percent level, whereas black tea, coffee, and milk are not significant. In the case of total expenditure, with the exception of fruit and vegetable juice, all other beverages are significant at the 1 percent level. As for the quadratic log-linear expenditure, green tea $(0.174)$, tea beverage (-0.015), coffee beverage (-0.027), carbonated beverage $(-0.020)$ and milk $(0.174)$ are significant at the 1 percent level. Black tea, coffee, and fruit and vegetable juice are not significant. The estimated $R^{2}$ results were satisfactory. They ranged from 0.222 for black tea equation to 0.669 for tea beverage equation indicating the model explains well the expenditure shares and prices for the non-alcoholic beverage in the household budget. 
Table 2. Estimates of expenditure and price coefficients

\begin{tabular}{|c|c|c|c|c|c|c|c|c|c|c|c|}
\hline \multirow{2}{*}{$\begin{array}{l}\text { Left-hand variable } \\
w_{i}\end{array}$} & \multicolumn{11}{|c|}{ Regressor } \\
\hline & $\log p_{1}$ & $\log p_{2}$ & $\log p_{3}$ & $\log p_{4}$ & $\log p_{5}$ & $\log p_{6}$ & $\log p_{7}$ & $\log p_{8}$ & $\log \frac{y}{P^{C}}$ & $\frac{1}{P^{z}}\left(\log \frac{y}{P^{c}}\right)^{2}$ & $R^{2}$ \\
\hline \multirow[t]{2}{*}{ Green tea } & $-0.127^{* * *}$ & -0.014 & 0.008 & -0.004 & 0.021 & $0.090^{* * *}$ & 0.022 & 0.006 & $0.134^{* * *}$ & $0.173^{* * *}$ & 0.598 \\
\hline & $(-3.890)$ & $(-0.812)$ & $(0.325)$ & $(-0.372)$ & $(0.965)$ & $(3.271)$ & $(1.011)$ & $(0.227)$ & $(32.280)$ & $(15.094)$ & \\
\hline \multirow[t]{2}{*}{ Black tea } & & -0.003 & 0.004 & $-0.006^{*}$ & -0.008 & 0.009 & -0.001 & $0.016^{*}$ & $0.006^{* * *}$ & $0.002(0.709)$ & 0.222 \\
\hline & & $(-0.604)$ & $(0.618)$ & $(-1.659)$ & $(-1.252)$ & $(1.103)$ & $(-0.193)$ & $(1.847)$ & $(5.061)$ & & \\
\hline \multirow[t]{2}{*}{ Tea beverage } & & & $-0.103 * * *$ & -0.010 & $-0.037 * * *$ & $-0.046^{* * *}$ & $0.034^{* * *}$ & 0.001 & $-0.017^{* * *}$ & $-0.015 * *$ & 0.669 \\
\hline & & & $(-7.990)$ & $(-1.421)$ & $(-3.092)$ & $(-3.007)$ & $(2.882)$ & $(0.041)$ & $(-7.383)$ & $(-2.426)$ & \\
\hline \multirow[t]{2}{*}{ Coffee } & & & & 0.010 & $0.037^{* *}$ & 0.017 & $0.028^{*}$ & 0.008 & $0.010^{* * *}$ & -0.005 & 0.549 \\
\hline & & & & $(1.150)$ & (2.394) & $(0.860)$ & $(1.797)$ & $(0.385)$ & $(3.235)$ & $(-0.652)$ & \\
\hline \multirow[t]{2}{*}{ Coffee beverage } & & & & & $-0.019^{*}$ & -0.002 & $-0.027 * * *$ & $0.060^{* * *}$ & $-0.007 * * *$ & $-0.028 * * *$ & 0.544 \\
\hline & & & & & $(-1.936)$ & $(-0.146)$ & $(-2.658)$ & $(4.624)$ & $(-3.393)$ & $(-5.158)$ & \\
\hline \multirow[t]{2}{*}{ Fruit \& vegetable juice } & & & & & & $0.042^{*}$ & 0.022 & $-0.160^{* * *}$ & 0.004 & $0.004(0.448)$ & 0.512 \\
\hline & & & & & & (1.897) & $(1.260)$ & $(-7.183)$ & $(1.241)$ & & \\
\hline \multirow[t]{2}{*}{ Carbonated beverage } & & & & & & & $-0.133^{* * *}$ & $0.084^{* * *}$ & $-0.009 * * *$ & $-0.021^{* * *}$ & 0.614 \\
\hline & & & & & & & $(-14.699)$ & (7.249) & $(-4.964)$ & $(-4.294)$ & \\
\hline \multirow[t]{2}{*}{ Milk } & & & & & & & & 0.023 & $-0.120^{* * *}$ & $0.173^{* * *}$ & \\
\hline & & & & & & & & $(0.933)$ & $(-29.404)$ & $(15.090)$ & \\
\hline
\end{tabular}

Note. The degrees of freedom of the demand system are 53,595. The corresponding critical values of the $t$-distribution for $1 \%, 5 \%, 10 \%$ significance levels are $2.576,1.960$, and 1.645 , respectively. $* * *, * *$, and * mean that the estimate is different from zero at the $1 \%, 5 \%$, and $10 \%$ significance levels, respectively. Defined as the squared correlation between the observed and predicted shares, $R^{2}$ is computed for each single equation. $t$-values are in parentheses.

The estimates of expenditure and uncompensated price elasticities are shown in Table 3. The expenditure elasticity for green tea (2.320), black tea (1.357), tea beverage (0.836), coffee (1.090), coffee beverage (0.896), fruit and vegetable juice (1.019), carbonated beverage (0.844) and milk (0.677) are all significant at the 1 percent level. More precisely, the expenditure elasticity for green tea, black tea, coffee and fruit and vegetable juice are elastic, while tea beverage, coffee beverage, carbonated beverage and milk are expenditure inelastic. In other words, green tea, black tea, coffee and fruit and vegetable juice are luxuries while tea beverage, coffee beverage, carbonated beverage and milk are necessities. This means that for instance a 1 percent increase in the non-alcoholic beverage expenditures increases demand for green tea by 2.320 percent and black tea by 1.357 percent respectively. 
Table 3. Estimates of expenditure and uncompensated price elasticities at the mean shares

\begin{tabular}{|c|c|c|c|c|c|c|c|c|c|}
\hline \multirow{2}{*}{$\begin{array}{l}\text { Demand } \\
q_{i}\end{array}$} & \multicolumn{9}{|c|}{ Price $p_{j}$} \\
\hline & $\begin{array}{l}\text { Expenditure } \\
y\end{array}$ & Green tea & Black tea & $\begin{array}{l}\text { Tea } \\
\text { beverage }\end{array}$ & Coffee & $\begin{array}{l}\text { Coffee } \\
\text { beverage }\end{array}$ & $\begin{array}{l}\text { Fruit } \& \\
\text { vegetable juice }\end{array}$ & $\begin{array}{l}\text { Carbonated } \\
\text { beverage }\end{array}$ & Milk \\
\hline \multirow[t]{2}{*}{ Green tea } & $2.320^{* * *}$ & $-2.795 * * *$ & $-0.203^{* *}$ & $0.835^{* * *}$ & $-0.427 * * *$ & $0.338^{* * *}$ & $0.601 * * *$ & -0.019 & $-0.651^{* * *}$ \\
\hline & $(56.276)$ & $(-9.882)$ & $(-2.448)$ & $(6.061)$ & $(-5.146)$ & $(2.758)$ & $(3.381)$ & $(-0.173)$ & $(-3.444)$ \\
\hline \multirow[t]{2}{*}{ Black tea } & $1.357^{* * *}$ & $-1.064 * *$ & $-1.344 * * *$ & $0.812^{* * *}$ & $-0.489^{* * *}$ & -0.375 & $0.893^{* *}$ & 0.109 & 0.102 \\
\hline & $(18.783)$ & $(-2.240)$ & $(-4.483)$ & $(2.542)$ & $(-2.735)$ & $(-1.329)$ & $(2.233)$ & $(0.405)$ & $(0.246)$ \\
\hline \multirow[t]{2}{*}{ Tea beverage } & $0.836^{* * *}$ & $1.000^{* * *}$ & $0.154 * * *$ & $-1.976^{* * *}$ & 0.016 & $-0.423 * * *$ & $-0.483^{* * *}$ & $0.673^{* * *}$ & 0.202 \\
\hline & $(35.837)$ & $(7.115)$ & $(2.705)$ & $(-15.585)$ & $(0.301)$ & $(-5.428)$ & $(-4.207)$ & $(9.330)$ & $(1.523)$ \\
\hline \multirow[t]{2}{*}{ Coffee } & $1.090^{* * *}$ & $-0.277^{* * *}$ & $-0.076^{* *}$ & -0.010 & $-1.009^{* * *}$ & -0.008 & $0.652^{* * *}$ & $-0.086^{* *}$ & $-0.276^{* * *}$ \\
\hline & (39.440) & $(-3.545)$ & $(-2.574)$ & $(-0.208)$ & $(-18.993)$ & $(-0.186)$ & $(9.193)$ & $(-2.093)$ & $(-3.540)$ \\
\hline \multirow[t]{2}{*}{ Coffee beverage } & $0.896^{* * *}$ & $0.665^{* * *}$ & -0.093 & $-0.646^{* * *}$ & 0.008 & $-1.242^{* * *}$ & $-0.460^{* * *}$ & $-0.236^{* *}$ & $1.108^{* * *}$ \\
\hline & (29.867) & (3.509) & $(-1.224)$ & $(-5.476)$ & $(0.116)$ & $(-8.568)$ & $(-3.068)$ & $(-2.440)$ & (7.016) \\
\hline \multirow[t]{2}{*}{ Fruit \& vegetable juice } & $1.019^{* * *}$ & $0.459 * * *$ & $0.091^{* *}$ & $-0.277 * * *$ & $0.387^{* * *}$ & $-0.171^{* * *}$ & $-0.656^{* * *}$ & -0.013 & $-0.840^{* * *}$ \\
\hline & (55.933) & $(4.710)$ & $(2.387)$ & $(-4.490)$ & $(9.399)$ & $(-3.213)$ & $(-5.771)$ & $(-0.263)$ & $(-9.345)$ \\
\hline \multirow[t]{2}{*}{ Carbonated beverage } & $0.844 * * *$ & 0.115 & 0.042 & $1.153^{* * *}$ & $-0.135^{*}$ & $-0.264^{* *}$ & -0.010 & $-3.281 * * *$ & $1.534^{* * *}$ \\
\hline & (27.867) & $(0.610)$ & $(0.514)$ & $(9.317)$ & $(-1.756)$ & $(-2.407)$ & $(-0.060)$ & $(-23.466)$ & $(9.627)$ \\
\hline \multirow[t]{2}{*}{ Milk } & $0.677^{* * *}$ & -0.011 & 0.017 & $0.069^{* *}$ & -0.036 & $0.208^{* * *}$ & $-0.353^{* * *}$ & $0.247^{* * *}$ & $-0.818^{* * *}$ \\
\hline & (61.564) & $(-0.217)$ & $(0.855)$ & $(1.963)$ & $(-1.592)$ & $(7.512)$ & $(-7.936)$ & (10.000) & $(-12.397)$ \\
\hline
\end{tabular}

Note. The same as Table 2 .

As for the uncompensated own- price elasticities, all eight beverages are significant at the 1 percent level. With the exception of fruit and vegetable juice and milk, which are own-price inelastic, all other beverages are own-price elastic. More specifically, carbonated beverage has the most own-price elastic and fruit and vegetable juice has the most own-price inelastic. This implies that if prices for green tea, black tea, tea beverage, coffee, coffee beverage, and carbonated beverage are lowered, total expenditure will increase since to the quantity sold will augment by large percentage than the decrease in price (see Table 3). Whereas for fruit and vegetable juice and milk, the indication is that a fall in price of the beverages will affect a smaller percentage change in quantity demanded. Using the LA/QUAIDS model, Dharmasena et al. (2009) also found the own-price elasticity of coffee to be elastic at -1.64 . Moreover, Zheng and Kaiser (2008) using the LA/AIDS model found the uncompensated price elasiticity for soft drinks (carbonated beverage) and milk to be price inelastic at -0.521 and -0.301 respectively, which is consistent with our results. Using Rotterdam and Translog demand system model, both Kinnucan et al. (2001) and Yen et al. (2004) also found carbonated beverage and milk to be price inelastic.

The uncompensated cross price elasticities shows that nineteen pairs are gross substitutes. Among the beverages group, tea beverage have the most number of substitutes whereas coffee has the least number of substitute pairs. The top pair of substitute is carbonated beverage and milk. This means that, for instance, a 1 percent increase in the price of carbonated beverage increases demand for milk by 1.534 percent, while a 1 percent increase in the price of milk increases demand for carbonated beverage by 0.247 percent. In addition, this result is consistent with Watanabe et al. (1997), who also found milk to be substitute with carbonated beverage in the Japanese household.

As for complementary beverages, twenty pairs are found to be gross complement in the beverages group. Coffee and fruit and vegetable juice have the most number of pairs among the group while black tea has the least number of complementary pair.

Table 4 reports the estimates of compensated price elasticities at the mean shares. All eight compensated own-price elasticities are significantly negative, which are consistent from theoretical perspective. As for the compensated cross price elasticities, twenty-four pairs are found to be significantly gross substitutes. Among the beverages group, tea beverage has the most number of pair and seems to be substitute with every other beverages with the exception of coffee beverage. Carbonated beverage has the least number of pair among the group. Moreover, sixteen pairs are found to be gross complements. Coffee beverage and fruit and vegetable juice have the most pairs among the beverage group while carbonated beverage and milk have the least number of pairs. One of the complementary pairs is milk and fruit and vegetable juice. This result is consistent with the studies of 
Yen et al. (2004), Zheng and Kaiser (2008), and Dharmasena et al. (2009). In their study, Yen et al. (2004) found milk as a complement to juice. Table 3 shows coffee and milk as gross complement however Table 4 shows they are gross substitute.

Table 4. Estimates of compensated price elasticities at the mean shares

\begin{tabular}{|c|c|c|c|c|c|c|c|c|}
\hline \multirow{2}{*}{$\begin{array}{l}\text { Demand } \\
q_{i}\end{array}$} & \multicolumn{8}{|c|}{ Price $p_{j}$} \\
\hline & Green tea & Black tea & $\begin{array}{l}\text { Tea } \\
\text { beverage }\end{array}$ & Coffee & $\begin{array}{l}\text { Coffee } \\
\text { beverage }\end{array}$ & $\begin{array}{l}\text { Fruit \& } \\
\text { Vegetable juice }\end{array}$ & $\begin{array}{l}\text { Carbonated } \\
\text { beverage }\end{array}$ & Milk \\
\hline \multirow[t]{2}{*}{ Green tea } & $-2.563^{* * *}$ & $-0.162^{*}$ & $1.063 * * *$ & $-0.179^{* *}$ & $0.489^{* * *}$ & $1.028^{* * *}$ & 0.114 & 0.210 \\
\hline & $(-9.075)$ & $(-1.956)$ & $(7.722)$ & $(-2.151)$ & $(3.988)$ & $(5.769)$ & $(1.059)$ & $(1.108)$ \\
\hline \multirow[t]{2}{*}{ Black tea } & $-0.927 *$ & $-1.320^{* * *}$ & $0.945^{* * *}$ & $-0.344^{*}$ & -0.287 & $1.142^{* * *}$ & 0.187 & 0.605 \\
\hline & $(-1.956)$ & $(-4.403)$ & $(2.963)$ & $(-1.922)$ & $(-1.017)$ & $(2.855)$ & $(0.695)$ & $(1.461)$ \\
\hline \multirow[t]{2}{*}{ Tea beverage } & $1.084^{* * *}$ & $0.169 * * *$ & $-1.894 * * *$ & $0.105^{* *}$ & $-0.368^{* * *}$ & $-0.329 * * *$ & $0.721 * * *$ & $0.512^{* * *}$ \\
\hline & $(7.722)$ & $(2.963)$ & $(-14.948)$ & $(1.980)$ & $(-4.733)$ & $(-2.866)$ & $(9.996)$ & $(3.855)$ \\
\hline \multirow[t]{2}{*}{ Coffee } & $-0.167^{* *}$ & $-0.056^{*}$ & $0.097^{* *}$ & $-0.892 * * *$ & 0.063 & $0.852^{* * *}$ & -0.024 & $0.128^{*}$ \\
\hline & $(-2.151)$ & $(-1.922)$ & $(1.980)$ & $(-16.738)$ & $(1.515)$ & (12.035) & $(-0.579)$ & $(1.646)$ \\
\hline \multirow[t]{2}{*}{ Coffee beverage } & $0.754^{* * *}$ & -0.077 & $-0.558^{* * *}$ & 0.104 & $-1.184 * * *$ & $-0.296^{* *}$ & $-0.184^{*}$ & $1.441^{* * *}$ \\
\hline & $(3.988)$ & $(-1.017)$ & $(-4.733)$ & $(1.515)$ & $(-8.171)$ & $(-1.970)$ & $(-1.908)$ & $(9.107)$ \\
\hline \multirow[t]{2}{*}{ Fruit \& vegetable juice } & $0.561^{* * *}$ & $0.109^{* * *}$ & $-0.176^{* * *}$ & $0.496^{* * *}$ & $-0.105^{* *}$ & $-0.469^{* * *}$ & 0.045 & $-0.462 * * *$ \\
\hline & $(5.769)$ & $(2.855)$ & $(-2.866)$ & (12.035) & $(-1.970)$ & $(-4.120)$ & $(0.920)$ & $(-5.144)$ \\
\hline \multirow[t]{2}{*}{ Carbonated beverage } & 0.200 & 0.057 & $1.236^{* * *}$ & -0.045 & $-0.209^{*}$ & 0.145 & $-3.233^{* * *}$ & $1.847^{* * *}$ \\
\hline & $(1.059)$ & $(0.695)$ & $(9.996)$ & $(-0.579)$ & $(-1.908)$ & $(0.920)$ & $(-23.117)$ & $(11.577)$ \\
\hline \multirow[t]{2}{*}{ Milk } & 0.057 & 0.029 & $0.136^{* * *}$ & $0.037^{*}$ & $0.252 * * *$ & $-0.229 * * *$ & $0.286^{* * *}$ & $-0.567^{* * *}$ \\
\hline & (1.108) & $(1.461)$ & $(3.855)$ & (1.646) & $(9.107)$ & $(-5.144)$ & $(11.577)$ & $(-8.579)$ \\
\hline
\end{tabular}

Note. The same as Table 2 .

Table 5 reports the estimates of monthly rates of shift and demographic effects at the mean shares. The effect of the linear time trend $(\mathrm{t})$ on demand is the monthly rate of shift. Five of the eight beverages are shown to have a significant effect on quantity demanded. With the exception of black tea, coffee beverage, and fruit and vegetable juice, all other beverages are significant at the 1 percent level. As time goes by, demand for green tea $(0.182)$, tea beverage $(0.166)$, coffee $(0.175)$, and carbonated beverage $(0.146)$ increases while demand for milk $(-0.179)$ decreases in the household. When the household size increases $\left(Z_{1}\right)$, demand is positive for coffee beverage (10.563), carbonated beverage (22.601), and milk (4.271), while it is negative for green tea (-26.647), and black tea (-20.559). When the household size is younger $\left(Z_{2}\right)$, demand for fruit and vegetable juice (12.752) and milk (5.928) is positive while demand for green tea (-13.115), tea beverage $(-6.584)$, coffee $(-9.630)$, and coffee beverage $(-16.821)$ is negative. Intuitively, this is true; as in Japan children tend to drink milk due its many nutritional values and health benefit. This result is consistent with Watanabe et al. (1997) who found younger people, larger families, and people with calcium distress consume more milk than any other segment of the household. In addition, they mentioned that increase of consumption of milk among age group has a lot to do with breakfast habits, as people are more likely to consume milk during breakfast than any other meal. When there are more elders in the household $\left(Z_{3}\right)$, demand for green tea (24.427) and milk (10.438) is positive while black tea (-11.045), tea beverage (-8.452), coffee (-23.999), coffee beverage (-17.447), and carbonated beverage $(-20.530)$ is negative. This is true as far as Japan is concerned since elderly people tend to be more conscious on their health and diet and beverages such as green tea and milk contribute to that aspect. This finding is also consistent with Watanabe et al. (1997) findings of positive relationship between health concerns and preferences for milk demand for elderly people. When the household head is older $\left(\mathrm{Z}_{4}\right)$, demand for green tea $(0.807)$, coffee $(0.840)$, carbonated beverage $(0.582)$ and milk $(0.407)$ are positive while demand for tea beverage $(-0.864)$, coffee beverage $(-1.781)$, and fruit and vegetable juice $(-0.926)$ are negative. When the percentage of those paying rents increases $\left(Z_{5}\right)$, demand for tea beverage $(0.093)$, coffee beverage $(0.231)$, fruit and vegetable juice $(0.166)$, and carbonated beverage $(0.339)$ is positive while demand for coffee $(-0.091)$, and milk $(-0.205)$ is negative. 
Table 5. Estimates of monthly rates of shift and demographic effects at the mean shares

\begin{tabular}{|c|c|c|c|c|c|c|}
\hline \multirow[b]{2}{*}{$\begin{array}{l}\text { Demand } \\
q_{i}\end{array}$} & \multicolumn{6}{|c|}{ Demographic variable $z_{k}$} \\
\hline & $\begin{array}{l}\text { Monthly rate of } \\
\text { shift } \\
(\% / \text { month })\end{array}$ & $\begin{array}{l}\text { Number of } \\
\text { persons per } \\
\text { household } \\
(\% / \text { person })\end{array}$ & $\begin{array}{l}\text { Number of persons } \\
\text { under the age of } 18 \\
(\% / \text { person })\end{array}$ & $\begin{array}{l}\text { Number of persons } \\
\text { per household over } \\
\text { the age of } 65 \\
\text { (\%/person) }\end{array}$ & $\begin{array}{l}\text { Age of the head } \\
(\% / \text { year old })\end{array}$ & $\begin{array}{l}\text { Rate of those } \\
\text { paying rents } \\
(\%)\end{array}$ \\
\hline Green tea & $0.182 * * *(2.852)$ & $-26.647 * * *(-5.495)$ & $-13.115^{*}(-1.941)$ & $24.427 * * *(3.463)$ & $0.807 *(1.756)$ & $0.085(1.080)$ \\
\hline Black tea & $0.176(1.273)$ & $-20.559 * *(-2.420)$ & $0.264(0.022)$ & $-11.045^{*}(-0.893)$ & $0.890(1.105)$ & $0.172(1.242)$ \\
\hline Tea beverage & $0.166^{* * *}(3.420)$ & $0.272(0.099)$ & $-6.584 *(-1.719)$ & $-8.452 * *(-2.114)$ & $-0.864 * * *(-3.317)$ & $0.093 * *(2.076)$ \\
\hline Coffee & $0.175^{* * *}(7.763)$ & $-2.071(-0.634)$ & $-9.630 * *(-2.116)$ & $-23.999 * * *(-5.052)$ & $0.840^{* * *}(2.716)$ & $-0.091 *(-1.708)$ \\
\hline Coffee beverage & $-0.015(-0.281)$ & $10.563^{* * *}(2.990)$ & $-16.821 * * *(-3.417)$ & $-17.447^{* * *}(-3.392)$ & $-1.781 * * *(-5.320)$ & $0.231 * * *(4.022)$ \\
\hline Fruit \& vegetable juice & $0.014(0.499)$ & $-1.845(-0.860)$ & $12.752 * * *(4.266)$ & $-2.267(-0.726)$ & $-0.926^{* * *}(-4.558)$ & $0.166^{* * *}(4.763)$ \\
\hline Carbonated beverage & $0.146^{* *}(2.548)$ & $22.601^{* * *}(6.337)$ & $-7.993(-1.608)$ & $-20.530 * * *(-3.953)$ & $0.582 *(1.720)$ & $0.339 * * *(5.837)$ \\
\hline Milk & $-0.179^{* * *}(-10.414)$ & $4.271^{* * *}(3.296)$ & $5.928 * * *(3.282)$ & $10.438^{* * *}(5.536)$ & $0.407^{* * *}(3.317)$ & $-0.205^{* * *}(-9.714)$ \\
\hline
\end{tabular}

Note. The same as Table 2.

Table 6 shows the estimates of temperature effects at the mean shares. Temperature shows negative effects on demand of green tea and black tea in most of the months whereas coffee is negatively significant all year round. Moreover, temperature for tea beverage, coffee beverage, fruits and vegetable juice and carbonated beverage mostly show positive effects. This is true with regards to Japan as beverages such as tea beverage, coffee beverage, fruit and vegetable juice and carbonated beverage are usually served cold whereas green tea, black tea and coffee are usually served hot through vending machine. For instance, carbonated beverages such as coca-cola and sprite are usually preferred during a hot temperature whereas drinks such as green tea or black tea are preferable during a cold temperature. As for the demand of milk, it is only significant in the month of July. One possible explanation for could be milk is not usually served in the vending machine.

Table 6. Estimates of temperature $\left({ }^{\circ} \mathrm{C}\right)$ effects at the mean shares

\begin{tabular}{|c|c|c|c|c|c|c|}
\hline Demand $q_{i}$ & January & February & March & April & May & June \\
\hline Green tea & $-0.390(-0.788)$ & $-0.196(-0.439)$ & $0.095(0.200)$ & $-0.054(-0.101)$ & $4.025^{* * *}(5.196)$ & $-1.825 * *(-2.000)$ \\
\hline Black tea & $-0.938(-1.082)$ & $-0.546(-0.695)$ & $0.420(0.504)$ & $-2.434 * *(-2.590)$ & $-0.794(-0.584)$ & $-3.397 * * *(-3.397)$ \\
\hline Tea beverage & $0.755^{* * *}(2.692)$ & $0.704 * * *(2.772)$ & $1.071 * * *(3.976)$ & $2.369^{* * *}(7.800)$ & $0.722(1.643)$ & $1.322 * *(2.556)$ \\
\hline Coffee & $-1.496^{* * *}(-4.493)$ & $-1.255^{* * *}(-4.168)$ & $-1.939^{* * *}(-6.071)$ & $-2.344 * * *(-6.510)$ & $-2.499 * * *(-4.789)$ & $-3.190^{* * *}(-5.194)$ \\
\hline Coffee beverage & $0.247(0.684)$ & $0.634 *(1.945)$ & $1.132 * * *(3.273)$ & $1.285^{* * *}(3.293)$ & $0.381(0.674)$ & $1.355^{* *}(2.037)$ \\
\hline Fruit \& vegetable juice & $0.433^{* *}(1.981)$ & $0.299(1.512)$ & $0.266(1.265)$ & $0.311(1.315)$ & $-0.468(-0.468)$ & $1.008 * *(2.495)$ \\
\hline Carbonated beverage & $-0.240(-0.659)$ & $-0.385(-1.169)$ & $0.169(0.483)$ & $0.089(0.226)$ & $-0.634(-1.112)$ & $-1.112 *(1.910)$ \\
\hline Milk & $0.160(1.211)$ & $0.054(0.456)$ & $-0.127(-0.998)$ & $-0.216(-1.507)$ & $-0.258(-0.258)$ & $0.289(1.184)$ \\
\hline Demand $q_{i}$ & July & August & September & October & November & December \\
\hline Green tea & $-3.381 * * *(-6.130)$ & $-1.377 * *(-2.086)$ & $-2.568^{* * *}(-4.507)$ & $-3.778 * * *(-7.252)$ & $-0.817 *(-1.707)$ & $2.043^{* * *}(4.367)$ \\
\hline Black tea & $-1.788 *(-1.838)$ & $-0.518(-0.447)$ & $-1.583(-1.586)$ & $-1.611 *(-1.757)$ & $-0.122(-0.145)$ & $0.567(0.691)$ \\
\hline Tea beverage & $2.095^{* * *}(6.699)$ & $2.214^{* * *}(5.916)$ & $0.610 *(1.889)$ & $1.495^{* * *}(5.057)$ & $1.293^{* * *}(4.749)$ & $1.304^{* * *}(4.913)$ \\
\hline Coffee & $-1.771 * * *(-4.784)$ & $-3.215^{* * *}(-7.232)$ & $-2.228^{* * *}(-5.808)$ & $-2.560 * * *(-7.302)$ & $-2.169^{* * *}(-6.745)$ & $-3.020^{* * *}(-9.583)$ \\
\hline Coffee beverage & $1.326 * * *(3.297)$ & $1.456^{* * *}(3.023)$ & $0.411(0.990)$ & $1.220 * * *(3.209)$ & $-0.127(-0.361)$ & $0.011(0.033)$ \\
\hline Fruit \& vegetable juice & $2.106^{* * *}(8.631)$ & $0.577^{* *}(1.974)$ & $1.319^{* * *}(5.236)$ & $1.644 * * *(7.129)$ & $0.923^{* * *}(4.351)$ & $4.351(0.384)$ \\
\hline Carbonated beverage & $1.511^{* * *}(3.721)$ & $0.359(0.740)$ & $1.991^{* * *}(4.748)$ & $2.128^{* * *}(5.543)$ & $1.152^{* * *}(3.258)$ & $-1.606^{* * *}(-4.665)$ \\
\hline Milk & $-0.555^{* * *}(-3.769)$ & $0.140(0.795)$ & $0.217(1.423)$ & $0.082(0.591)$ & $-0.104(-0.810)$ & $0.188(1.504)$ \\
\hline
\end{tabular}

Note. The same as Table 2. 
The highest negative temperature effects are particularly seen in the month of July, September and October on green tea, April, June, and July on black tea, June, August, and December on coffee. To give an example, demand for green tea decreases by -2.568 percent in September as temperature rises by 1 degree Celsius. As for positive effects is concerned, it is mostly high in July and August both on tea beverage and coffee beverage, from July to October for fruit and vegetable juice, and from September to October for carbonated beverage. For instance, as temperature rises by 1 degree Celsius, demand for tea beverage increases by 2.095 percent in the month of July.

With the exception of milk, temperature effect is mostly significant for all other beverages. Moreover, these effects positive and negative are higher during the summer seasons.

\section{Conclusion}

This study using the LA/QUAIDS model analyzed the demand for non-alcoholic beverages in Japan for eight beverages group using monthly data obtained from FIES. The estimated results reveal that expenditure elasticities for green tea, black tea, coffee, and fruit and vegetable juice are elastic while tea beverage, coffee beverage, carbonated beverage, and milk are inelastic. This implies that green tea, black tea, coffee, and fruit and vegetable juice are luxuries whereas tea beverage, coffee beverage, carbonated beverage, and milk are necessities in the household. The empirical results for uncompensated own-price elasticities show that demand for green tea, black tea, tea beverage, coffee, coffee beverage, and carbonated beverage are own-price elastic while demand for fruit and vegetable juice and milk are inelastic. The cross price elasticities for both uncompensated and compensated show that most of the beverages are complement to each other. As for socio-demographic effect is concerned, it is found to play a key role in the determinant of the non-alcoholic beverages consumption. The results reveal that people under the age of 18 prefer milk and fruit and vegetable juice than any other beverages, while elderly people prefer more green tea in addition to milk. This indicates that in the Japanese household demand, there is a strong association between consumer behavior and its health and dietary implication. With regards to seasonal effects, the study reveals that when temperature rises, people consume more tea beverage, coffee beverage, fruit and vegetable juice, and carbonated beverage whereas when temperature drops consumers prefer more green tea, black tea and coffee. In reality, this is true since green tea, black tea, and coffee are usually served hot and consumed at home whereas beverages such as tea beverage, coffee beverage, fruit and vegetable juice and carbonated beverage are served cold and are frequently consumed in convenience shops and through vending machines.

The findings of our study have an implication for policy. Milk is set to be good for health, and as our findings show coffee beverage and carbonated beverage are substitutes for milk. Consequently, milk consumption will increase if the government taxes coffee beverage and carbonated beverage.

\section{Acknowledgements}

This research was supported by Grant-in-Aid for Scientific Research (C), no. 25450323, Japanese Ministry of Education, Culture, Sports, Science and Technology.

\section{References}

Agnew, M. D., \& Palutikof, J. P. (1999). The impacts of climate on retailing in the UK with particular reference to the anomalously hot summer and mild winter of 1995. International Journal of Climatology, 19, 1493-1507. http://dx.doi.org/10.1002/(SICI)1097-0088(19991115)19:13<1493::AID-JOC455>3.0.CO;2-V

Alston, J. M., Chalfant, J. A., \& Piggott, N. E. (2001). Incorporating demand shifters in the almost ideal demand system. Economics Letters, 70, 73-78. http://dx.doi.org/10.1016/S0165-1765(00)00322-0

Bahng, Y., \& Kincade, D. H. (2012). The relationship between temperature and sales: Sales data analysis of a retailer of branded women's business wear. International Journal of Retail \& Distribution Management, 40(6), 410-426. http://dx.doi.org/10.1108/09590551211230232

Banks, J., Blundell, R. W., \& Lewbel, A. (1997). Quadratic Engel curves and consumer demand. Review of Economics and Statistics, 79, 527-539. http://dx.doi.org/10.1162/003465397557015

Deaton, A. (1985). Panel data from time series of cross-sections. Journal of Econometrics, 30, 109-126. http://dx.doi.org/10.1016/0304-4076(85)90134-4

Deaton, A. S., \& Muellbauer, J. (1980). An almost ideal demand system. The American Economic Review, 70, 312-326.

Dharmasena, S., Capps Jr, O., \& Clauson, A. (2009). Nutritional contributions of non-alcoholic beverages to the U.S. Diet: 1998-2003. In Southern Agricultural Economics Association Annual Meeting, Atlanta, GA. 
Harrison, K. (1992). Whether the weather be good. Super Marketing, 15-17.

Helgi Library. (2011). Data on Tea Consumption Per Capita. Retrieved from http://helgilibrary.com/indicators/index/bean-consumption-per-capita

Japan Soft Drink Association. (2014). Statistical Beverage Data 2014. Retrieved from http://j-sda.or.jp/about-jsda/business-scheme.php

Kinnucan, H. W., Miao, Y., Xiao, H., \& Kaiser, H. M. (2001). Effects of advertising on US non-alcoholic beverage demand: Evidence from a two-stage Rotterdam model. Advances in Applied Microeconomics, 10, 1-29. http://dx.doi.org/10.1016/S0278-0984(01)10002-7

Matsuda, T. (2006). Linear approximations to the quadratic almost ideal demand system. Empirical Economics, 33, 663-675. http://dx.doi.org/10.1007/s00181-005-0044-3

Ministry of Agriculture, Forestry and Fisheries. (MAFF). Current situation of (milk) consumption. Japan. Retrieved from http://www.dairy.co.jp/jp/eng06.pdf

Murray, K. B., Di Muro, F., Finn, A., \& Popkowski Leszczyc, P. (2010). The effect of weather on consumer spending. Journal of Retailing and Consumer Services, 17(6), 512-520. http://dx.doi.org/10.1016/j.jretconser.2010.08.006

Parker, P. M., \& Tavassoli, N. T. (2000). Homeostasis and consumer behavior across cultures. International Journal of Research in Marketing, 17, 33-53. http://dx.doi.org/10.1016/S0167-8116(00)00006-9

Pofahl, G. M., Capps Jr, O., \& Clauson, A. (2005). Demand for non-alcoholic beverages: Evidence of from the ACNielsen home scan panel. American Agricultural Economics Association annual meeting, Providence, RI.

Pollak, R. A., \& Wales, T. J. (1980). Comparison of the quadratic expenditure system and translog demand systems with alternative specifications of demographic effects. Econometrica, 595-612. http://dx.doi.org/10.2307/1913125

Pollak, R. A., \& Wales, T. J. (1992). Demand System Specification and Estimation. Oxford University Press Catalogue. http://dx.doi.org/10.1007/978-94-011-1795-1_6

Roslow, S., Li, T., \& Nicholls, J. A. F. (2000). Impact of situational variables and demographic attributes in two seasons on purchase behavior. European Journal of Marketing, 34, 1167-1180. http://dx.doi.org/10.1108/03090560010342548

Schluep Campo, I., \& Beghin, J. C. (2005). Dairy food and consumption, production, and policy in Japan. Food and Agricultural Policy Research Instititute (FAPRI) at Iowa State University.

Statista. (2014). Per capita consumption of soft drinks in United States from 2000 to 2013. Retrieved from http://www.statista.com/statistics/306836/us-per-capita-consumption-of-soft-drinks/

Stroppiana, R., Riethmuller, P., \& Kobayashi, K. (1998). Regional Differences in the Japanese Diet: The Case of Drinking Milk. Economic Analysis and Policy, 28, 85-102. http://dx.doi.org/10.1016/S0313-5926(98)50006-9

Watanabe, Y., Suzuki, N., \& Kaiser, H. M. (1997). Identifying consumer characteristics associated with Japanese preferences toward milk products. Agribusiness, 13(4), 357-363. http://dx.doi.org/10.1002/(SICI)1520-6297 (199707/08)13:4<357::AID-AGR1>3.0.CO;2-Y

Watanabe, Y., Suzuki, N., \& Kaiser, H. M. (1998). Factors affecting consumers' choice of beverages in Japan. Agribusiness, 14(2), 147-156. http://dx.doi.org/10.1002/(SICI)1520-6297(199803/04)14:2<147::AID-AGR $7>3.0 . \mathrm{CO} ; 2-2$

Watanabe, Y., Suzuki, N. (2006). Is Japan's milk consumption saturated? Journal of the Faculty of Agriculture Kyushu University, 51(1), 165-171.

Yen, S. T., Lin, B. H., Smallwood, D. M., \& Andrews, M. (2004). Demand for nonalcoholic beverages: The case of low-income households. Agribusiness, 20, 309-321. http://dx.doi.org/10.1002/agr.20015

Zheng, Y., \& Kaiser, H. M. (2008). Advertising and U.S. nonalcoholic beverage demand. Agricultural and Resource Economics Review, 37, 147-159. 


\section{Copyrights}

Copyright for this article is retained by the author(s), with first publication rights granted to the journal.

This is an open-access article distributed under the terms and conditions of the Creative Commons Attribution license (http://creativecommons.org/licenses/by/3.0/). 